\title{
Supercritical phase inversion of starch-poly(e-caprolactone) for tissue engineering applications
}

\author{
Ana Rita C. Duarte · João F. Mano • \\ Rui L. Reis
}

Received: 1 July 2009/Accepted: 6 October 2009/Published online: 20 October 2009

(C) Springer Science+Business Media, LLC 2009

\begin{abstract}
In this work, a starch-based polymer, namely a blend of starch-poly(e-caprolactone) was processed by supercritical assisted phase inversion process. This processing technique has been proposed for the development of 3D structures with potential applications in tissue engineering applications, as scaffolds. The use of carbon dioxide as non-solvent in the phase inversion process leads to the formation of a porous and interconnected structure, dry and free of any residual solvent. Different processing conditions such as pressure (from 80 up to 150 bar) and temperature $\left(45\right.$ and $\left.55^{\circ} \mathrm{C}\right)$ were studied and the effect on the morphological features of the scaffolds was evaluated by scanning electron microscopy and micro-computed tomography. The mechanical properties of the SPCL scaffolds prepared were also studied. Additionally, in this work, the in vitro biological performance of the scaffolds was studied. Cell adhesion and morphology, viability and proliferation was assessed and the results suggest that the materials prepared are allow cell attachment and promote cell proliferation having thus potential to be used in some for biomedical applications.
\end{abstract}

A. R. C. Duarte · J. F. Mano - R. L. Reis

Department of Polymer Engineering, 3B's Research GroupBiomaterials, Biodegradables and Biomimetics, University of Minho, Headquarters of the European Institute of Excellence on Tissue Engineering and Regenerative Medicine, AvePark, Zona Industrial da Gandra, S. Cláudio do Barco, 4806-909 Caldas das Taipas, Guimarães, Portugal

A. R. C. Duarte $(\bowtie) \cdot$ J. F. Mano · R. L. Reis

IBB-Institute for Biotechnology and Bioengineering, PT Associated Laboratory (Laboratório Associado), Braga, Portugal e-mail: aduarte@dep.uminho.pt

\section{Introduction}

The design and development of new materials for tissue engineering applications presents a great challenge and is moving towards an interdisciplinary research field, as new approaches to combine cells, biomaterials, and bioactive compounds are key for the success in regenerative medicine $[1,2]$. Scaffolds are no longer merely a physical inert support but should play a role in cell proliferation and differentiation, providing the necessary information or signaling for cell attachment, proliferation and differentiation, in order to meet the requirement of dynamic reciprocity for tissue engineering.

A wide range of materials has been proposed for biomedical applications, from metals to ceramics and polymers. Natural polysaccharides, such as starch, cellulose derivatives, chitin, chitosan, hyaluronic acid and alginate are among the natural polymers receiving considerable attention to be used in tissue engineering, due to their high biocompatibility, biodegradability and hydrophilicity. [3] Among these, biocompatibility plays a very important role as it will ultimately determine the nature of the host response and graft survival. These nature-derived polymers have previously proved to be the right choice for these applications, mainly due to their low immunogenic potential and chemical/biological versatility.

Starch-based polymers have been studied in our group for a wide range of bone-related therapy applications, ranging from tissue engineering scaffolds [4-7], to bone cements $[8,9]$ and drug delivery systems. [10, 11] Their natural origin, together with their mechanical properties and biocompatibility support the potential of starch-based materials in the biomedical field.

The polymeric blend of starch and poly( $\varepsilon$-caprolactone) (SPCL) takes advantages of the properties of natural based 
polymers, namely starch, which is one of the most abundantly occurring natural polymers and the synthetic component, poly( $\varepsilon$-caprolactone), is a biodegradable aliphatic polyester currently used in an array of biomedical applications.

One of the most important stages of tissue engineering is the processing of a porous 3D structure, with high porosity, high interconnectivity between the porous and uniform distribution. Several techniques are reported in the literature for the preparation of 3D scaffolds [12]. Conventionally, three-dimensional structures can be obtained by processes such as solvent casting - particle leaching [13], freeze-drying - particle leaching [14], thermally induced phase separation [15], compression moulding [5, 16], injection moulding [6, 17], extrusion [18], foaming [19], wet spinning [20] and electrospinning [21], among others. The advantages of these processes have, however, to be weight against the fact that these normally involve the use of large amounts of organic solvents, and further purification and drying steps are often needed. Additionally, some of these techniques are performed at high temperatures. For these reasons, there is the need to develop new technologies that are able to avoid or reduce the use of organic solvents and that operate at mild conditions are of great interest. Supercritical fluid technology has been proposed, in the past years, as an interesting alternative for the preparation of matrixes for processing of biopolymers and biomedical devices [22-24]. From the techniques available, the most commonly used for the preparation of 3D scaffolds for tissue engineering purposes include gas foaming and phase inversion processes.

The phase inversion technique involves casting of a polymer solution onto an inert support followed by immersion of the support with the cast film into a bath filled with a non-solvent for the polymer. The contact between the solvent and the non-solvent causes the phase separation. One of the most important advantages of the use of carbon dioxide as a non-solvent is the fact that simply by tuning the processing conditions, i.e. pressure and temperature, one can tailor the final structure of the product. Supercritical assisted phase inversion technique presents further advantages over the conventional phase inversion process, namely the fact that porosity and interconnectivity are induced in the samples at the same time that the material is precipitated from the organic solvent. Additionally, the material is recovered in the dry state, which avoids the use of any additional drying steps, reducing the processing energy consumption and leading to more efficient processes.

Supercritical assisted phase inversion has been successfully applied in the preparation of membranes from synthetic polymers, namely poly-L-lactic acid (PLLA) [25, 26], poly-methylmethacrylate (PMMA) [27], Nylon 6 [28], PS
[29], cellulose acetate [30, 31], polysulfone [32, 33] and polycarbonate/polyethyleneglycol [34]. Recently, different studies in the literature report the successful processing of natural based polymers using this technique. Temtem et al. [35] reported the precipitation of chitosan membranes from an aqueous solution of dilute acetic acid. 3D chitosan structures have also been processed from different organic solutions [36]. Another study reports the preparation of scaffolds of a polymeric blend of starch and poly-L-lactic acid from a chloroform solution with potential applications in tissue engineering [37].

In this work, the possibility of processing a commercial blend of starch-poly- $\varepsilon$-caprolactone using supercritical fluid technology was evaluated. The effect of the operating conditions on morphology of the scaffolds prepared was analyzed and its in vitro citotoxicity of the materials processed was studied.

\section{Experimental procedure}

\subsection{Supercritical assisted phase-inversion process}

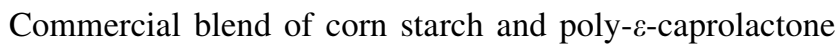
(SPCL), 30:70 wt\%, in granular form was used to perform the experiments. A solution of $15 \mathrm{wt} \%$ is prepared dissolving SPCL in chloroform (Pronalab, Portugal).

The phase inversion experiments were carried out in an apparatus especially for this purpose and presented in a previous work [37]. In each experiment a small amount (ca. $2 \mathrm{ml}$ ) of the polymer solution was loaded in a stainless steel cap with $2 \mathrm{~cm}$ diameter, which is placed inside the high pressure vessel. The vessel is heated in by means of an electric thin band heater (OGDEN) connected to a temperature controller, that maintains temperature within $\pm 1^{\circ} \mathrm{C}$. Carbon dioxide (99.998 mol\% purity, Air Liquide) is pumped into the vessel using high pressure piston pump (P-200A Thar Technologies) until the operational pressure is attained. The pressure inside the vessel is measured with a pressure transducer. The system was closed for $45 \mathrm{~min}$ to allow the occurrence of phase separation. Afterwards the system is flushed for another $45 \mathrm{~min}$, with a stream of carbon dioxide at very low flow rate $(5 \mathrm{~g} / \mathrm{min})$, in order to ensure complete drying of the scaffolds. The flow is regulated by a flow meter (Siemens, SITRANS FC MASS FLO MASS2100).

\subsection{Scaffold characterization}

\subsubsection{Scanning electron microscopy (SEM)}

Samples of the scaffolds prepared were observed by a Leica Cambridge S360 SEM. The matrixes were fixed by 
mutual conductive adhesive tape on aluminium stubs and covered with gold palladium using a sputter coater.

\subsubsection{Micro-computed tomography ( $\mu$-CT)}

The inner structure, porosity and interconnectivity were evaluated by micro-computerized tomography using a micro CT scanner (Skyscan 1702, Belgium) with penetrative X-rays of $40 \mathrm{keV}$. The X-ray scans were acquired in high-resolution mode. CT Analyser ${ }^{\circledR}$ software was used to visualize and reconstruct the $2 \mathrm{D}$ X-ray sections images of the scaffolds.

\subsubsection{Mechanical properties}

Compressive mechanical properties of the scaffolds prepared were measured using an INSTRON 5540 (Instron Int. Ltd., High Wycombe, UK). The compressive modulus is defined as the initial linear modulus on the stress/strain curves. The data presented is the result of the average of at least three measurements. Statistical analysis was performed to compare the results obtained. One-way ANOVA was performed using GraphPad Prism version 4.00 for Windows, GraphPad Software, San Diego, California USA, www.graphpad.com. The results were considered statistically significant when $\mathrm{P}<0.05$.

\subsection{In vitro studies}

\subsubsection{Cell seeding and culture}

A mouse lung fibroblast cell line (L929 cell line, European Collection of Cell Cultures, UK), were maintained in DMEM (Dulbecco's modified Eagle's medium; SigmaAldrich, Germany) supplemented with $10 \%$ heat-inactivated fetal bovine serum (Biochrom AG, Germany) and $1 \%$ antibiotic-antimycotic solution (Gibco, UK). Cells were cultured in a humidified incubator at $37^{\circ} \mathrm{C}$ in a $5 \%$ $\mathrm{CO}_{2}$ atmosphere.

Confluent cells were harvested and seeded in the polymeric scaffolds as follows. SPCL scaffolds are distributed in a 48 -well cell culture plate $\left(\right.$ Costar $^{\circledR}$, Corning, USA). Initially, immersed in sterile PBS for one hour in order to swell the matrix. After PBS is replaced by $1 \mathrm{ml}$ of a suspension of fibroblast-like cells with a concentration of $1 \times 10^{5}$ cells $/ \mathrm{ml}$. The fibroblasts/scaffold constructs were statically cultured for 1,3 and 7 days under the culture conditions previously described.

\subsubsection{Cell adhesion and morphology}

To evaluate the cell morphology, the cells-scaffold constructs were fixed with $4 \%$ formalin (Sigma-Aldrich,
Germany) for 15 min and then were washed with PBS. Afterwards, SPCL scaffolds were dehydrated through a graded series of ethanol and allowed to dry overnight. Finally, they were sputter-coated and analysed by SEM.

\subsubsection{Cell viability assay}

The cell viability was determined using the MTS assay. This assay is based on the bioreduction of a tetrazolium compound, 3-(4,5-dimethylthiazol-2-yl)-5-(3-carboxymethoxyphenyl)2-(4-sulphofenyl)-2H-tetrazolium (MTS) (Promega, USA), into a water-soluble brown formazan product. This was quantified by UV-spectroscopy, reading the formazan absorbance at $490 \mathrm{~nm}$ in a microplate reader (Bio-Tek, Synergie HT, USA). Results were compared to the cell viability on the tissue culture polystyrene plate, as means of assay control. Unseeded scaffolds were used as sample control (data not shown). Three samples per time point were analysed.

\subsubsection{DNA quantification}

Cell proliferation was evaluated by quantifying the total amount of double-stranded DNA present in the fibroblast/ scaffold construct, at the different culture times. Quantification was performed using the Quant-iT ${ }^{\mathrm{TM}}$ PicoGreen $^{\circledR}$ dsDNA Assay Kit (Molecular Probes, Invitrogen, USA) after cell lysis by osmotic and thermal shock. The fluorescence was measured at an excitation wavelength of 485/ $20 \mathrm{~nm}$ and at an emission wavelength of $528 / 20 \mathrm{~nm}$, in a microplate reader. The DNA concentration for each sample was calculated using a standard calibration curve. Results were compared to the cell proliferation on the tissue culture polystyrene plate as means of assay control. Unseeded scaffolds were used as sample control (data not shown). Experiments were carried out in three replicates.

Statistical analysis was performed to compare the results obtained using GraphPad Prism version 4.00 for Windows, GraphPad Software, San Diego, California USA, www.graphpad.com. Shapiro-Wilk test was used to verify the normality of the data obtained and as the results follow a normal distribution one-way ANOVA with Bonferroni post-test was performed to compare the results from the different time points. The results were considered statistically significant when $P<0.05$.

\section{Results and discussion}

In this study the possibility of using supercritical fluid technology for the preparation of SPCL scaffolds with potential applications in tissue engineering was evaluated. The supercritical assisted phase inversion technique was chosen to perform these experiments as it presents some 
advantages over the conventional phase inversion process, namely the fact that porosity and interconnectivity are induced in the samples at the same time that the material is precipitated from the organic solvent. Furthermore, the material is recovered in the dry state, which avoids the use of any additional drying steps, reducing the processing energy consumption and leading to more efficient processes. In order to evaluate the effect of some operating conditions on the production of SPCL scaffolds different experiments were carried out. The operating conditions for the supercritical assisted phase inversion process were chosen following the analysis of the vapour-liquid equilibrium data of the binary system carbon dioxide + chloroform [38]. Ensuring that the process conditions fall in the phase region of total miscibility between carbon dioxide and chloroform we can predict the successful occurrence of the phase inversion and the production of dry scaffolds. The morphology and topography of the scaffolds prepared was analysed by SEM and $\mu$-CT analysis. SEM analysis provides micrographs of the cross section of the materials prepared (Fig. 1).

The morphology of the scaffolds prepared is characterized by a smooth surface with some pores, which was similar in all the tested conditions at $45^{\circ} \mathrm{C}$. The matrixes present a rough inner structure with micro- and macropores, which can encourage cell attachment and proliferation. Ideal scaffolds for bone tissue engineering require three-dimensionally interconnected porous structures, so nutrients and oxygen can be accessible to the cells together with the elimination of cell wastes. A major limitation in tissue engineering is the failure to induce rapid vascular ingrowth during tissue development. The viability of cells that migrate into the scaffold from the native tissue is highly dependent on transport of nutrients and waste products between the cells and the host tissue [39]. Therefore, the high interconnectivity of the implant is extremely important for the success of the bone defect repairment. The SPCL matrixes produced by supercritical assisted phase inversion are also characterized by an interconnected porous structure, which can be quantitatively determined by $\mu$-CT.

Micro-computed tomography allows a better visualization of the inner structure, porosity and interconnectivity, of the matrixes prepared. A representative $2 \mathrm{D}$ image of the SPLC matrixes prepared at $80 \mathrm{bar}$ and $45^{\circ} \mathrm{C}$ and $150 \mathrm{bar}$ and $55^{\circ} \mathrm{C}$ is presented in Fig. 2. Furthermore the 3D reconstruction of these scaffolds is also shown.

From these images it is already possible to conclude that a macroporous structure is homogeneous throughout all the volume of the samples, additionally SPCL matrixes produced at $45^{\circ} \mathrm{C}$ present higher porosity and interconnectivity. The interconnectivity is defined as the volume of the disconnected pores higher than $50 \mu \mathrm{m}$, which is the optimum diameter for cell migration and nutrients transport. Table 1 summarizes the results obtained for samples processed under different operating conditions.
Fig. 1 SEM images of the SPCL scaffolds a cross section of the matrix prepared at 150 bar and $45^{\circ} \mathrm{C}$, b cross section of the sample prepared at $150 \mathrm{bar}$ and $55^{\circ} \mathrm{C}$
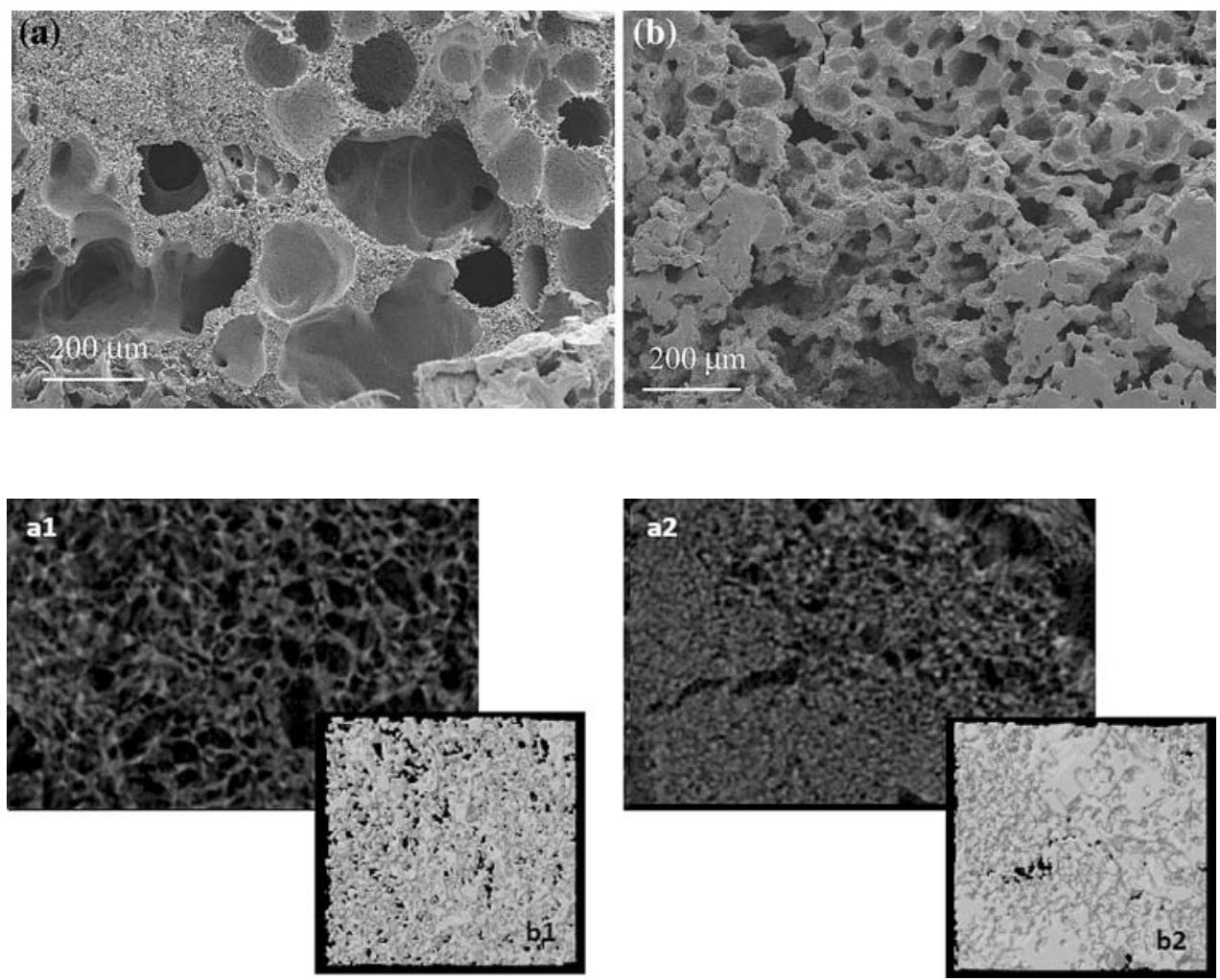

Fig. 2 Representative micro CT images of SPCL matrixes prepared at 80 bar and $45^{\circ} \mathrm{C}(1)$ and 150 bar and $55^{\circ} \mathrm{C}(2)$ : a $2 \mathrm{D}$ surface and $\mathbf{b} 3 \mathrm{D}$ model 
Table 1 Summary of morphological analysis of the SPCL samples prepared

\begin{tabular}{llclll}
\hline Polymer & Experiment & $P($ bar $)$ & $\mathrm{T}\left({ }^{\circ} \mathrm{C}\right)$ & Porosity $(\%)$ & Interconnectivity (\%) \\
\hline SPCL 30:70 & 1 & 80 & 45 & 64 & 65 \\
15 wt\% & 2 & 100 & 45 & 75 & 67 \\
& 3 & 150 & 45 & 53 & 40 \\
& 4 & 150 & 55 & 62 & 23 \\
\hline
\end{tabular}

The effect of pressure on the scaffold porosity was studied for the system SPCL (15 wt\% polymer solution) at $45^{\circ} \mathrm{C}$. Pressure effect is related to the solvent power of carbon dioxide. As pressure increases, there is a higher amount of carbon dioxide present in the system and the solubility of the non-solvent in the organic solution increases. Consequently the viscosity of the polymer solution decreases, which leads to the coarsening of the solution. Coarsening is caused by diffusion of polymer and solvent and is often associated with spinodal decomposition [40, 41]. This process leads to larger porosity and interconnectivity and will ultimately lead to a shift towards larger pore sizes as pressure increases. At higher pressures there is however a decrease in porosity, which has also been observed in the preparation of SPLA matrixes [37].

Regarding the temperature effect, when experiments were performed at $55^{\circ} \mathrm{C}$, the scaffolds produced present smaller pores (Fig. 2) and lower porosity (Table 1). This can be explained due to the vicinity of the experimental temperature with the melting temperature of poly- $\varepsilon$-caprolactone, which is $60^{\circ} \mathrm{C}$. It is known that carbon dioxide has a plasticizing effect on certain polymers. Studies report the use of gas-foaming technique to process PCL scaffolds with potential applications in tissue engineering. Microcellular foams of PCL have been prepared and are reported by Jenkins et al. [42] Leonard et al. [43] also report a study on the characterization of porous structures of biodegradable scaffolds using supercritical carbon dioxide as a foaming agent. The plasticization of this polymer might be the reason for a different morphology when SPCL is processed at higher temperatures. However, even though PCL might be plasticized at $55^{\circ} \mathrm{C}$, the presence of semi-crystalline corn starch in the polymeric blend does not allow foaming of this mixture.

Figure 3 represents the effect of pressure on the pore size distribution of the matrixes, prepared by supercritical phase inversion at $45^{\circ} \mathrm{C}$. The pore size distribution was evaluated by micro-CT analysis.

The pore size of the scaffolds prepared at 80 bar follows a Gaussian distribution, indicating that the matrixes are more homogeneous than the ones prepared at higher pressures. At 100 and 150 bar there is a broad particle size distribution, which is shifted towards larger pores, when the materials were processed at 100 bar. On the contrary,

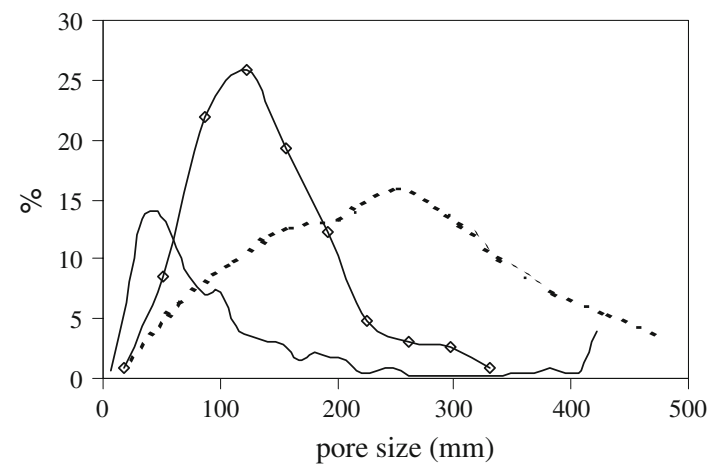

Fig. 3 Pressure effect on pore size distribution in the SPCL scaffolds prepared by supercritical fluid assisted phase at $45^{\circ} \mathrm{C}$ : symbol 80 bar, dashed line 100 bar, solid line 150 bar

at 150 bar the matrixes present smaller pores, which may be a result of the plasticizing effect of carbon dioxide on PCL.

The suggested mechanism responsible for the morphology of porous matrixes by phase inversion is the liquid-liquid demixing. However, the attribution of a specific structure in the membrane to a certain phase separation process is rather complicated [44]. Different mass transport mechanisms are involved in these regions and for that reason different polymeric matrixes can be obtained [45].

The majority of the matrixes are prepared by controlled phase separation of polymer solutions in two phases: one with a high polymer concentration and one with a low polymer concentration. A proposed mechanism of membranes formation indicates that a porous cellular structure is obtained if $\mathrm{L}-\mathrm{L}$ demixing by nucleation and growth of the droplets of a polymer lean phase occurs [44].

The morphology of the SPCL matrixes obtained by supercritical assisted phase inversion method can be considered as a bicontinuos structure. Besides the macropores $(>150 \mu \mathrm{m})$ one can also identify the existence of micropores $(<50 \mu \mathrm{m})$. The mechanism proposed for the precipitation of these interconnected pore structures is a spinodal decomposition, nevertheless this is still object of discussion and another hypothesis is that the bicontinuos structures are a result of coalescence of polymer poor droplets generated by binodal decomposition.

Mechanical properties of the samples prepared were evaluated and compression tests were performed to the 


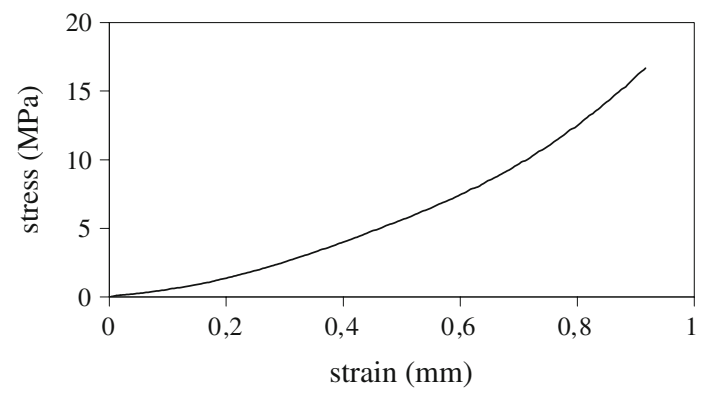

Fig. 4 Representative stress deformation curve of SPCL $15 \mathrm{wt} \%$ sample prepared at $45^{\circ} \mathrm{C}$ and $80 \mathrm{bar}$

Table 2 Mechanical properties of the SPCL matrixes prepared (standard deviation error is also presented)

\begin{tabular}{lll}
\hline Pressure (bar) & Temperature $\left({ }^{\circ} \mathrm{C}\right)$ & Compressive modulus $(\mathrm{MPa})$ \\
\hline 80 & 45 & $0.37( \pm 0.04)$ \\
150 & 45 & $0.37( \pm 0.06)$ \\
150 & 55 & $0.32( \pm 0.02)$ \\
\hline
\end{tabular}

samples prepared at different processing conditions. Figure 4 shows, as an example, a representative curve for the deformation behaviour of the porous matrixes, namely for a SPCL sample prepared at 80 bar and $45^{\circ} \mathrm{C}$.

The microstructural characteristics of the scaffold influence its mechanical properties. Usually, stress-strain curves for an open cellular material, in compression, present a linear elastic regime, a plateau and a densification regime [46, 47]. Beyond elastic limit permanent deformation will occur. This corresponds to the point when pores start to collapse and the structure is irreversibly damaged. The stress deformation curve of SPCL scaffolds prepared by supercritical fluid assisted phase inversion, is not typical as densification of cell structure appears to start in the initial steps of compression. The compressive modulus was calculated it is presented in Table 2. The results shown are a mean value of at least three experiments.

Samples prepared at different conditions present a compressive modulus, whose difference is not statistically significant $(P<0.05)$. In general, this material presents good mechanical properties to support cell adhesion, which has also been demonstrated in different studies reported in the literature $[18,48,49]$.

\subsection{In vitro studies}

Morphological and topological properties of the SPCL scaffolds prepared at 80 bar and $45^{\circ} \mathrm{C}$ demonstrate the potential of these scaffolds to be used for tissue engineering applications. Apart from favorable morphological and mechanical properties, the most important requirement for a polymer to be used in the biomedical area is its biocompatibility. Therefore, in vitro citotoxicity of the materials needs to be assessed. Cell viability and metabolic activity was assessed by MTS in the SPCL scaffolds prepared by supercritical assisted phase inversion. Enzymes present in metabolically active cells are responsible for the conversion of MTS into formazan. The amount of formazan product, is therefore, directly related to the number of living cells present in the scaffolds. Figure 5a represents the trend of cell viability as a function of time. Cell culture proliferation was studied by quantification of the amount of double-stranded DNA present in the seeded scaffolds at the pre-determined time points. Figure $6 \mathrm{~b}$ represents the DNA content on the seeded scaffolds. The trend observed for the DNA content is quite similar to the cell viability as expected.

Figure 5 shows that MTS assay is in agreement with the DNA biochemical analysis performed. Statistical analysis allows us to conclude that cell viability and proliferation is significantly different from days 1 and 3 to day 7. This result indicates that there is in fact cell growth on the surface of the material prepared.

Scanning electron microscopy allows the visualization of the cell morphology and its spatial distribution within the polymeric matrix. Figure 6 represents a SEM image of the cultured SPCL scaffolds, with fibroblasts.

After 7 days of culture the SPCL scaffold presented a good interaction with cells in which a layer of fibroblasts could be detected, covering the surface of the construct.
Fig. 5 Cell viability and proliferation on SPCL scaffolds after 1, 3 and 7 days culture a MTS assay and b DNA content
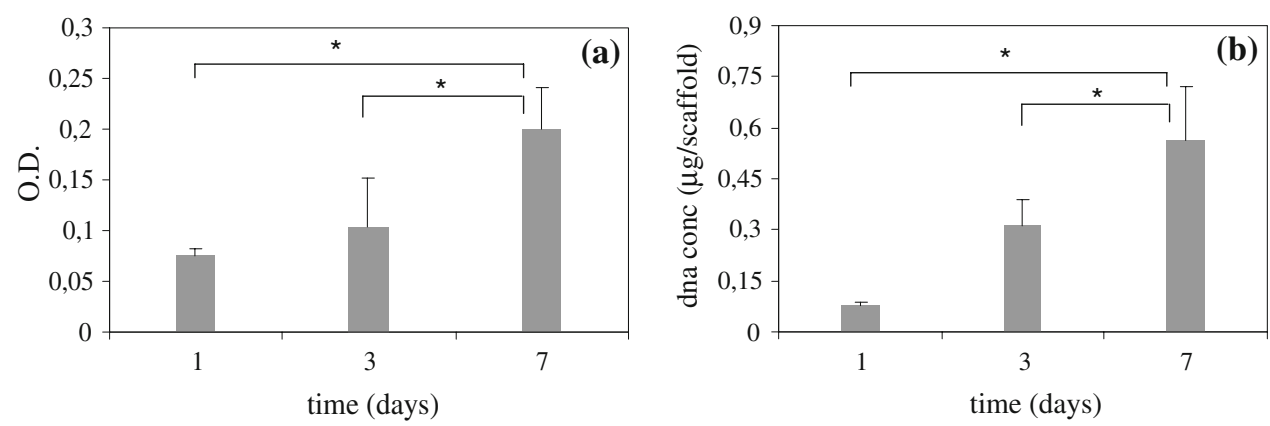


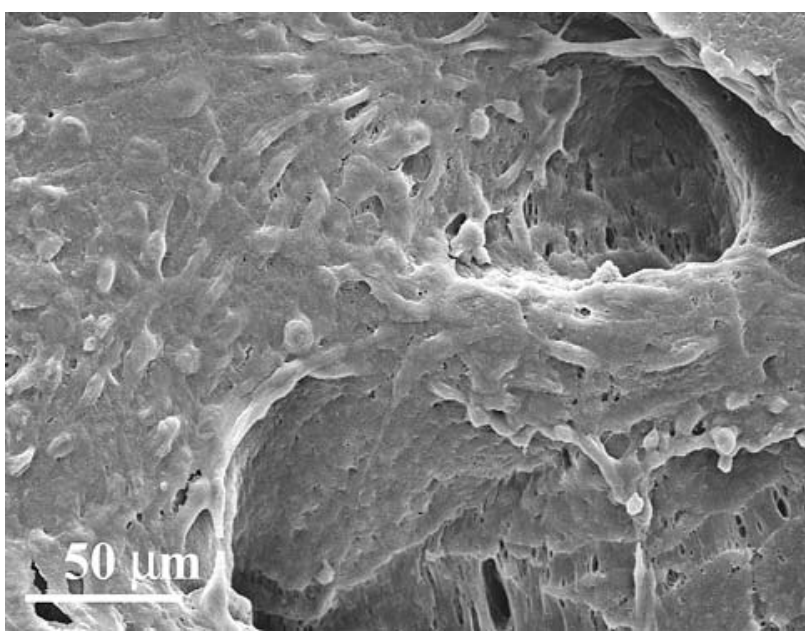

Fig. 6 SEM image of SPLC scaffolds cultured for 7 days with fibroblasts-like cells (L929 cell line)

In addition, it can be seen that cells did not obstruct the pores of the scaffold. This is an indication that cells may grow into the bulk of the material without compromising the delivery of nutrients and the elimination of toxic products to and from the core of the matrix. These observations point out that further culturing time would be necessary for fibroblast growth into the bulk of the scaffold.

From the results obtained we can conclude that SPCL scaffolds prepared by supercritical assisted phase inversion are non-cytotoxic and furthermore are able to support cell growth and proliferation.

\section{Conclusions}

In this work, a polymeric blend of starch and poly( $\varepsilon$-caprolactone) (SPCL) was processed using supercritical assisted phase inversion. Different parameters that influence this technique were tested. Scaffolds prepared with SPCL 30:70 wt \% show that a bicontinuous structure if formed which indicates that the mechanism governing the precipitation of these interconnected pore structures is the spinodal decomposition. The porosity and the interconnectivity of the scaffolds could be tuned up to a certain extent by changing pressure and temperature. Due to the low melting temperature of SPCL, the scaffolds processed at $55^{\circ} \mathrm{C}$ presented a more compact structure with low interconnectivity. For this reason, the best operating temperature for the processing of SPCL scaffolds was $45^{\circ} \mathrm{C}$. Pore size distribution is also influenced by the phase inversion processing conditions and a more homogeneous scaffold was obtained when the process was carried out at lower pressures.

Fibroblasts were seeded and cultured in the scaffolds and in vitro studies demonstrate that SPCL scaffolds prepared by supercritical assisted phase inversion are not cytotoxic and can sustain cell growth and proliferation.

Acknowledgments Ana Rita C. Duarte is grateful for financial support from Fundação para a Ciência e Tecnologia through the grant SFRH/BPD/34994/2007.

\section{References}

1. Hutmacher DW. Scaffold design and fabrication technologies for engineering tissues - state of the art and future perspectives. J Biomat Sci Polym Ed. 2001;12(1):107-24.

2. Liu XH, Ma PX. Polymeric scaffolds for bone tissue engineering. Ann Biomed Eng. 2004;32(3):477-86.

3. Mano JF, Silva GA, Azevedo HS, Malafaya PB, Sousa RA, Silva SS, et al. Natural origin biodegradable systems in tissue engineering and regenerative medicine: present status and some moving trends. J R Soc Interface. 2007;4(17):999-1030.

4. Salgado AJ, Coutinho OP, Reis RL, Davies JE. In vivo response to starch-based scaffolds designed for bone tissue engineering applications. J Biomed Mater Res A. 2007;80A(4):983-9.

5. Ghosh S, Viana JC, Reis RL, Mano JF. The double porogen approach as a new technique for the fabrication of interconnected poly(L-lactic acid) and starch based biodegradable scaffolds. J Mater Sci Mater Med. 2007;18(2):185-93.

6. Ghosh S, Vianac JC, Reis RL, Mano JF. Development of porous lamellar poly(L-lactic acid) scaffolds by conventional injection molding process. Acta Biomater. 2008;4(4):887-96.

7. Silva GA, Coutinho OP, Ducheyne P, Shapiro IM, Reis RL. Starch-based microparticles as a novel strategy for tissue engineering applications. Key Eng Mater. 2006;309-311:907-10.

8. Boesel LF, Mano JF, Reis RL. Optimization of the formulation and mechanical properties of starch based partially degradable bone cements. J Mater Sci Mater Med. 2004;15(1):73-83.

9. Boesel LF, Mano JF, Elvira C, San Roman J, Reis RL. Hydrogels and hydrophilic partially degradable bone cements based on biodegradable blends incorporating starch. In: Chiellini E, editor. Biodegradable polymers and plastics. Dordrecht: Kluwer Academic; 2003.

10. Malafaya PB, Elvira C, Gallardo A, San Roman J, Reis RL. Porous starch-based drug delivery systems processed by a microwave route. J Biomat Sci Polym Ed. 2001;12(11):1227-41.

11. Malafaya PB, Stappers F, Reis RL. Starch-based microspheres produced by emulsion crosslinking with a potential media dependent responsive behavior to be used as drug delivery carriers. J Mater Sci Mater Med. 2006;17(4):371-7.

12. Moroni L, De Wijn JR, Van Blitterswijk CA. Integrating novel technologies to fabricate smart scaffolds. J Biomat Sci Polym Ed. 2008;19(5):543-72.

13. Fu Q, Rahaman MN, Dogan F, Bal BS. Freeze-cast hydroxyapatite scaffolds for bone tissue engineering applications. Biomed Mater. 2008;3:025005. doi:10.1088/1748-6041/3/2/025005.

14. Sultana N, Wang M. Fabrication of HA/PHBV composite scaffolds through the emulsion freezing/freeze-drying process and characterisation of the scaffolds. J Mater Sci Mater Med. 2008;19(7):2555-61.

15. Nakamatsu J, Torres FG, Troncoso OP, Yuan ML, Boccaccini AR. Processing and characterization of porous structures from chitosan and starch for tissue engineering scaffolds. Biomacromolecules. 2006;7(12):3345-55.

16. Ghosh S, Viana JC, Reis RL, Mano JF. Bi-layered constructs based on poly(L-lactic acid) and starch for tissue engineering of osteochondral defects. Mater Sci Eng C. 2008;28(1):80-6. 
17. Gomes ME, Ribeiro AS, Malafaya PB, Reis RL, Cunha AM. A new approach based on injection moulding to produce biodegradable starch-based polymeric scaffolds: morphology, mechanical and degradation behaviour. Biomaterials. 2001;22(9):883-9.

18. Gomes ME, Azevedo HS, Moreira AR, Ella V, Kellomaki M, Reis RL. Starch-poly(epsilon-caprolactone) and starch-poly(lactic acid) fibre-mesh scaffolds for bone tissue engineering applications: structure, mechanical properties and degradation behaviour. J Tissue Eng Regen Med. 2008;2(5):243-52.

19. Chevalier E, Chulia D, Pouget C, Viana M. Fabrication of porous substrates: a review of processes using pore forming agents in the biomaterial field. J Pharm Sci-Us. 2008;97(3):1135-54.

20. Tuzlakoglu K, Alves CM, Mano JF, Reis RL. Production and characterization of chitosan fibers and 3-D fiber mesh scaffolds for tissue engineering applications. Macromol Biosci. 2004;4(8):811-9.

21. Liang D, Hsiao BS, Chu B. Functional electrospun nanofibrous scaffolds for biomedical applications. Adv Drug Deliv Rev. 2007;59(14):1392-412.

22. Duarte ARC, Mano JF, Reis RL. Supercritical fluids in biomedical and tissue engineering applications: a review. Int Mater Rev. 2009;54(4):214-22.

23. Duarte ARC, Mano JF, Reis RL. Perspectives on: supercritical fluid technology for the preparation of 3D scaffolds for tissue engineering applications. J Bioact Compat Polym. 2009;24:385400.

24. Reverchon E, Adami R, Cardea S, Porta GD. Supercritical fluids processing of polymers for pharmaceutical and medical applications. J Supercrit Fluids. 2009;47(3):484-92.

25. Tsivintzelis I, Pavlidou E, Panayiotou C. Porous scaffolds prepared by phase inversion using supercritical $\mathrm{CO}_{2}$ as antisolventI. Poly(L-lactic acid). J Supercrit Fluids. 2007;40(2):317-22.

26. Tsivintzelis L, Marras SI, Zuburtikudis L, Panayiotou C. Porous poly(L-lactic acid) nanocomposite scaffolds prepared by phase inversion using supercritical $\mathrm{CO}_{2}$ as antisolvent. Polymer. 2007;48(21):6311-8

27. Reverchon E, Cardea S, Rappo ES. Production of loaded PMMA structures using the supercritical $\mathrm{CO}_{2}$ phase inversion process. J Membr Sci. 2006;273(1-2):97-105.

28. Kho YW, Kalika DS, Knutson BL. Precipitation of Nylon 6 membranes using compressed carbon dioxide. Polymer. 2001;42(14):6119-27.

29. Matsuyama H, Yano H, Maki T, Teramoto M, Mishima K, Matsuyama K. Formation of porous flat membrane by phase separation with supercritical $\mathrm{CO}_{2}$. J Membr Sci. 2001;194(2):157-63.

30. Reverchon E, Cardea S. Formation of cellulose acetate membranes using a supercritical fluid assisted process. J Membr Sci. 2004;240(1-2):187-95.

31. Matsuyama H, Yamamoto A, Yano H, Maki T, Teramoto M, Mishima $\mathrm{K}$, et al. Effect of organic solvents on membrane formation by phase separation with supercritical $\mathrm{CO}_{2}$. J Membr Sci. 2002;204(1-2):81-7.

32. Reverchon E, Cardea S. Formation of polysulfone membranes by supercritical $\mathrm{CO}_{2}$. J Supercrit Fluids. 2005;35(2):140-6.

33. Temtem M, Casimiro T, Aguiar-Ricardo A. Solvent power and depressurization rate effects in the formation of polysulfone membranes with $\mathrm{CO}_{2}$-assisted phase inversion method. J Membr Sci. 2006;283(1-2):244-52.
34. Kim MS, Lee SJ. Characteristics of porous polycarbonate membrane with polyethylene glycol in supercritical $\mathrm{CO}_{2}$ and effect of its porosity on tearing stress. J Supercrit Fluids. 2004;31(2):21725.

35. Temtem M, Silva LMC, Andrade PZ, dos Santos F, da Silva CL, Cabral JMS, et al. Supercritical $\mathrm{CO}_{2}$ generating chitosan devices with controlled morphology. Potential application for drug delivery and mesenchymal stem cell culture. J Supercrit Fluids. 2009;48(3):269-77.

36. Duarte ARC, Mano JF, Reis RL. Chitosan scaffolds prepared by supercritical assisted phase inversion for tissue engineering applications. In: 9th international symposium on supercritical fluids: 2009, Arcachon, France; 2009.

37. Duarte ARC, Mano JF, Reis RL. Preparation of starch-based scaffolds for tissue engineering by supercritical immersion precipitation. J Supercrit Fluids. 2009;49(2):279-85.

38. Peters CJ, Florusse LJ. Experimental-determination of vaporliquid-equilibria in binary-mixtures of carbon-dioxide plus chloroform. J Chem Eng Data. 1995;40(4):948-9.

39. Murphy WL, Peters MC, Kohn DH, Mooney DJ. Sustained release of vascular endothelial growth factor from mineralized poly(lactide-co-glycolide) scaffolds for tissue engineering. Biomaterials. 2000;21(24):2521-7.

40. Cao JH, Zhu BK, Ji GL, Xu YY. Preparation and characterization of PVDF-HFP microporous flat membranes by supercritical $\mathrm{CO}_{2}$ induced phase separation. J Membr Sci. 2005;266(1-2):102-9.

41. Randolph TW, Randolph AD, Mebes M, Yeung S. Submicrometer-sized biodegradable particles of poly(L-lactic acid) via the gas antisolvent spray precipitation process. Biotechnol Prog. 1993;9(4):429-35.

42. Jenkins MJ, Harrison KL, Silva MMCG, Whitaker MJ, Shakesheff KM, Howdle SM. Characterisation of microcellular foams produced from semi-crystalline PCL using supercritical carbon dioxide. Eur Polym J. 2006;42(11):3145-51.

43. Leonard A, Calberg C, Kerckhofs G, Wevers M, Jerome R, Pirard $\mathrm{JP}$, et al. Characterization of the porous structure of biodegradable scaffolds obtained with supercritical $\mathrm{CO}_{2}$ as foaming agent. J Porous Mater. 2008;15(4):397-403.

44. Reuvers AJ, van den Berg JWA, Smolders CA. Formation of membranes by means of immersion precipitation: part I. A model to describe mass transfer during immersion precipitation. J Membr Sci. 1987;34(1):45-65.

45. Kimmerle K, Strathmann H. Analysis of the structure-determining process of phase inversion membranes. Desalination. 1990;79(2-3):283-302.

46. Gibson LJ, Ashby MF. The mechanics of 3-dimensional cellular materials. Proc R Soc Lond Ser A. 1982;382(1782):43-59.

47. Gibson LJ. Biomechanics of cellular solids. J Biomech. 2005;38(3):377-99.

48. Gomes ME, Bossano CM, Johnston CM, Reis RL, Mikos AG. In vitro localization of bone growth factors in constructs of biodegradable scaffolds seeded with marrow stromal cells and cultured in a flow perfusion bioreactor. Tissue Eng. 2006;12(1):177-88.

49. Gomes ME, Holtorf HL, Reis RL, Mikos AG. Influence of the porosity of starch-based fiber mesh scaffolds on the proliferation and osteogenic differentiation of bone marrow stromal cells cultured in a flow perfusion bioreactor. Tissue Eng. 2006;12(4): 801-9. 